\title{
Commentary
}

\section{COVID-19 Crisis in Africa: Revisiting the Contributing Factors}

\author{
Ugochukwu A Eze ${ }^{1}$, Kingsley I Ndoh ${ }^{2}$, Kehinde K Kanmodi ${ }^{3,4}$ \\ 1. Department of Ophthalmology, Federal Medical Centre, Asaba, Nigeria \\ 2. Department of Global Health, University of Washington, Seattle, USA \\ 3. Cephas Health Research Initiative Inc, Ibadan, Nigeria \\ 4. School of Health and Life Sciences, Teesside University, Middlesbrough, UK
}

\begin{abstract}
The COVID-19 pandemic has been a major threat to people and healthcare systems around the world. Each region of the world has had unique factors such as culture, demographics, socioeconomic and the political landscape that has either fueled or mitigated the severity of the pandemic. For example, the 2021 Indian Kumbh Mela festival fueled a devastating wave of the pandemic in India. Similarly, the pandemic in the United States has in part been fueled an epidemic of disinformation that led to a growing number of anti-vaxxers, and those who are opposed to COVID-19 prevention guidelines set by agencies like the Centers for Disease Control and Prevention. In Africa, burial practices in Liberia and the Democratic Republic of Congo once fueled the Ebola epidemic. Likewise, in the context of COVID-19, there are factors that are unique to Africa that may have either fueled or mitigated the severity of the pandemic. The anti-COVID-19 measures in many African countries significantly affected household income without commensurate deployment of palliative measures to cushion the effect. Fortunately, the pandemic has run a relatively milder course in sub-Saharan Africa-defying earlier devastating projections. Therefore, to be prepared for the next pandemic, African governments must involve critical stakeholders such as religious and traditional leaders, strengthen current disease surveillance systems and invest in systems that encourage private investments in local vaccine manufacturing.
\end{abstract}

Keywords Perceptions, attitudes, practices, transmission, coronavirus, Africa

Citation Eze UA, Ndoh KI, Kanmodi KK. COVID-19 crisis in Africa: Revisiting the contributing factors. Ann Public Health Issues 2021;1:64-67. doi: 10.2478/aphi-2021-0006

Received: September 6, 2021

Revised: October 13, 2021

Accepted: October 13, 2021

Correspondence to:

Dr. Ugochukwu A Eze, MBBS, FMCOph

Department of Ophthalmology, Federal Medical Centre, Asaba, Nigeria

Email: ugorexeze@gmail.com

Mobile: +2347031557006

\section{Introduction}

The pandemic of the coronavirus disease 2019, otherwise known as COVID-19, is a 
public health crisis that has altered the lives of peoples in Africa and their interaction with each other and the outside world. According to the World Health Organization (WHO), as at August 24, 2021, over 212 million confirmed cases with over 4 million deaths had been recorded globally [1]. The WHO and other health-related organizations in various African countries have been and are actively involved in advocacy aimed at influencing people to change their perceptions and practices that may propagate and accelerate the spread of the dreaded coronavirus. The insights and data gains from understanding the African COVID-19 experience will be crucial in preparing for the next pandemic and/or regional epidemic.

\section{Factors Contributing to the Spread of COVID-19 in Africa}

In the words of the WHO Director-General, Tedros Ghebreyesus:

"We are deeply concerned both by alarming levels of spread and severity and by the alarming levels of inaction. We have rung the bell loud and clear" [2]

The above statement was directed at Africans, due to the communal way of life, cultural, social belief systems and practices, which makes Africans unique but may be their Achilles' heel and may contribute to the limitations in the global efforts to stem the spread of COVID-19. Also worrisome are the false beliefs, fake news and conspiracies in Africa that alleges COVID-19 as a hoax [3-5]. The negative economic effect of the serial lockdowns and the untold hardship heralded by the pandemic, has also contributed to its spread [6]. Other factors that have placed Africa in this precarious position include, but not limited to, wrong actions and inactions of many African governments, high rates of poverty and superstition [4,6-9].

There is no gain saying that governments have far reaching influence on the lives of people. However, the responses and perception of the public from the policies, guidelines and public health interventions about COVID-19 painted the opposite picture of such an influence. This was also partly due to the failure of contextualizing policies to fit everyday African realities. For example, it was not realistic for most of sub-Saharan Africa to be locked down for extended periods of time without adequate palliative measures from the government to cushion the effects of these lockdowns. Additionally, it was reported in several African countries, that government officials publicly flouted their own guidelines on social distancing rules and travel restrictions, but expected the populace to heed to it. This mistrust has continued to fester, especially from the plethora of alternative-oftentimes false-information coming from some religious leaders and media sources about the COVID-19 pandemic and vaccines $[3,9]$. A summation of these factors has made it difficult for 
political leaders to enforce the adherence of beneficial anti-COVID-19 plans and policies even when borne out of a good intention [3].

Secondly, critical stakeholders that heavily influenced African societies-such as religious and traditional leaders-were not adequately engaged by the government from the onset of the pandemic in the areas of advocacy and health education. This has led to a two-headed hydra of disinformation from influential religious leaders and questionable media sources. A recent survey by the World Bank showed that about $90 \%$ of Liberians will rather stick to prayers than take the COVID-19 vaccine [10]. Similarly, a video — which went viral and then was subsequently removed-by a prominent Nigerian pastor alleged the vaccine to be "the mark of the Beast". Allegations of corruption relating to COVID-19 funds had equally played a role. For example, the widely reported 2020 "palliative looting" in Nigeria and news of hyperinflated COVID-19 related contracts in the South Africa only deepens this mistrust and waters down the public health influence government is meant to have.

Furthermore, the social practices in Africa, such as religious rituals, marriage and burial festivals, are part the unique identity as Africans [7]. Africans are communal in nature and many people hold fast to these beliefs which have a bearing on their behaviors, which have most likely contributed to the spread of the infection. There is some evidence that physical and social distancing are effective ways of reducing the spread of infection but some of these are not practical in many parts of Africa [11]. Furthermore, even though African health bodies advised on good cough etiquette, hand hygiene, and rational use of facemasks, compliance to these measures fell short $[7,12]$. Nonetheless, there were some other African countries such as Rwanda where enforcement largely successful.

It is also noteworthy that a lot of African families are engaged in the informal sector of the economy, and rely on daily incomes to sustain their livelihood. This in part made prolonged lockdowns unrealistic, compounded by the fact that there were some reported deaths from hunger due to the lockdowns [13,14]. It has also been reported that the containment strategies in Africa which were mainly a replication of what happened in the rich Western countries and were deemed not to be effective [13]. These economic realities, beliefs and cultures underscores the need for African governments to take more Afrocentric approaches in tackling future pandemics.[15].

\section{Conclusion}

We have highlighted the COVID-19 crisis in Africa and have briefly discussed the factors that have negatively impacted public health efforts aimed at reducing spread 
of coronavirus infection in Africa. It is pertinent that the above-mentioned factors are dispassionately reviewed and studied and decisive actions that takes into cognizance of the unique African context to urgently stem the spate of community spread of COVID-19 as well as prepare Africa adequately for the next pandemic.

Author contributions: Study conceptualization - UAE; study protocol design - UAE, KIN, and KKK; manuscript drafting - UAE, KIN, and KKK; acceptance of final draft UAE, KIN, and KKK.

Funding: None.

Conflict of interest: KKK is the Editor-in-Chief of Annals of Public Health Issues. However, his position did not influence the editorial decisions made regarding this publication. Other authors - UAE and KIN - have no conflict of interest to declare.

\section{References}

[1] World Health Organization. WHO coronavirus (COVID-19) Dashboard. Available from: https://covid19.who.int/. Accessed 25 Aug. 2021.

[2] World Health Organization. WHO Director - General's opening remarks at the media briefing on COVID19 on 11 March 2020 [Online]. Available from: https://www.who.int/dg/speeches/. Assessed 23 Jul. 2020.

[3] Chatham House. Nigeria's political leaders need to win trust to tackle COVID-19 [Online]. Available from: https://www.chatamhouse.org/expert/comment/ Assessed 23 Jul. 2020.

[4] Kanmodi KK. Combating fake news on COVID-19 in Africa: Is punitive measures the best strategy? Yen Med J 2020;2(3):3-4.

[5] Romer D, and Jamieson KH. Conspiracy theories as barriers to controlling the spread of COVID-19 in the U.S. Soc Sci Med. 2020;263:113356.

[6] Olarinde $\mathrm{MO}$ and Amzat J. The infected economy: Interrogating the early economic impacts of COVID19 pandemic in Nigeria. Ann Public Health Issues 2021;1:50-63.

[7] Jaja IF, Anyanwu MU, and Iwu Jaja CJ. Social distancing: how religion, culture and burial ceremony undermine the effort to curb COVID-19 in South Africa. Emerg Microbes Infect. 2020;9(1):1077-1079.

[8] UNIDO. (2020) Tackling COVID-19 in Sub-Saharan Africa | Industrial Analytics Platform. [Online]. Available from: https://iap.unido.org/articles/. Assessed 23 Jul. 2020.

[9] Ezeibe CC, Ilo C, Ezeibe EN, Oguonu CN, Nwankwo NA, Ajaero CK, Osadebe N. Political distrust and the spread of COVID-19 in Nigeria. Glob Public Health. 2020;15(12):1753-1766.

[10] Menezes NP, Simuzingi M, Debebe ZY, Pivodic F, Massiah E. What is driving COVID-19 vaccine hesitancy in sub-Saharan Africa? World Bank Blogs. Available from: https://blogs.worldbank.org/africacan/whatdriving-covid-19-vaccine-hesitancy-sub-saharan-africa. Published 11 Aug. 2021. Accessed 12 Oct. 2021.

[11] Dashraath P, Wong JL, Lim MXK, Lim LM, Li S, Biswas A, Choolani M, Mattar C, Su LL. Coronavirus disease 2019 (COVID-19) pandemic and pregnancy. Am J Obstet Gynecol. 2020;222(6):521-531.

[12] FHI 360. Hand hygiene, cough etiquette, face mask, cleaning and laundry. [Online]. Available from: https://www.fhi.no/en/op/novel-coronavirus-facts-advice/. Assessed 23 Jul. 2020.

[13] UNIDO. Tackling COVID-19 in Sub-Saharan Africa | Industrial Analytics Platform. [Online]. Available from: https://iap.unido.org/articles/. Assessed 23 Jul. 2020.

[14] World Bank. The Global Economic Outlook during the COVID-19 Pandemic: A Changed World. [Online]. Available at https://www.worldbank.org/en/news/featue/2020. Assessed 23 Jul. 2020.

[15] Ndoh KI. Africa need Afrocentric solutions to beat COVID-19. Seattle Times. Available at https://www.seattletimes.com/opinion/africa-needs-afrocentric-solutions-to-beat-covid-19/ . Assessed 03 Oct. 2020. 